\title{
NOBEL PRIZE IN CHEMISTRY, 2020: THOUGHTS AND IMPLICATIONS
}

\author{
Agnita Kundu* \\ Assistant Professor, Department of Chemistry, Shri Shikshayatan College, Kolkata. West Bengal, \\ India
}

Corresponding Author: Dr. Agnita Kundu.

Article DOI: https://doi.org/10.36713/epra7399

DOI No: 10.36713/epra7399

\begin{abstract}
Nobel Prize is considered to be the most prestigious prize in the world of academics. Its influence is felt even in nonacademic world. This year the Nobel prize in Chemistry was shared by Dr. Emanual Charpentier and Dr, Jennifer Dudna for their invention of the method of gene slicing using CRISPER-CAS 9. The prize has several social, economic, academic implications apart from the obvious scientific implications. This prize being awarded for development of technology, has some added issues of patenting, cost, misuse related to it. These topics are interesting for people interested in science, specially to youngsters who are interested in science.
\end{abstract}

KEYWORDS: Science, Nobel prize, CRISPER.

\section{INTRODUCTION}

The Nobel prize of 2020 in Chemistry was won by Dr. Emanual Charpentier, a French microbiologist, working in Max Planck Institute of Infection Biology in Berlin, Germany and Dr. Jennifer Dudna an American biochemist from University of California, Berkeley. For the first time, two women have shared the Nobel prize in Chemistry [1]. They received the award for their discovery of a method for Gene slicing, using CRISPER-CAS 9. It is being referred to as a genetic scissor that can cut our genes in specific points accurately. This powerful technology has the power to do tremendous good as well as can be misused also. The financial implications of this discovery have led to conflicts about its patenting. This win has brought to the forefront the challenges faced by women in the upper echelons of science. It also reflects how the division of sciences have become obsolete and the importance of collaboration and communication in the scientific world. This gene slicing technology brings to light how research in basic science led to development of a technology and how this technology needs to be made available for common good. This article takes a look at different aspects of this win and how it encourages more women to science.

\section{DISCUSSION}

The invention: CRISPER/CAS 9 is a gene editing tool that is guided by RNA to target a DNA. It abbreviates to Cluster of Regularly Interspaced Short Palindromic Repeats and is clubbed with CRISPER Associated Genes. It is consists of a single guided RNA and CAS nuclease that is able to target DNA. This repetition of sequences was first observed in bacterial chromosomes that were protecting them from attacking viruses. Within these repeated sequence some portions were unique in nature. Origins of these unique sequences were traced back to a virus that had previously infected the bacteria. The reflection of this viral sequence gets imprinted within the bacterial immune system. When the virus attacks the bacteria again, it is able to fight off the viral infection with the help of its micro-RNA and the unique repeated sequence or CRISPER. Another set of sequence, CAS-9 or CRISPER Associated Sequence of genes is always present alongside these unique sequences. The CAS-9 nuclease and microRNA are responsible for destroying the viral 
DNA of the attacking virus. Hence, the combination of CRISPER-CAS 9 is able to identify a DNA sequence and cut it. Therefore, it was later developed as a technical tool. There are three types of CRISPER/CAS systems each with several subgroups. They consist of a CAS endonuclease, a CRISPER RNA (cr RNA) and a transactivating crRNA (tracr RNA). The latter two form a duplex structure, a guide RNA. This can be replaced by a synthetic single guide RNA (sg RNA) which consists of 20 unique base pair sequence that is complimentary to the targeted DNA They bind together by base pairing and CAS 9 precisely cleaves the DNA [2].

Use and possible Misuse: DNA is the storehouse of information of all our genetic traits. Hence, a technology as powerful as this has the potential to being used as well as abused. The efficiency and affordability of the technology makes it even more so. At its best it can be used to treat a number of serious diseases that are caused by genetic defect like sickle cell anaemia, thalassemia etc. It can also be used to develop crops with better growth, less infection. The main focus of the application in the field has been in agriculture and medicine. It can be used to genetically modify other species as well, which can lead to imbalance in environment and biodiversity. Genetically modified species can be potentially used in biological warfare The scientists are well aware of the potential misuse of this technology. To prevent that they are in the committees that will control the use of the product [3].

Women in Science: The world is reeling under the disease COVID-19, that is extremely infectious and one of the ways of containing it has been the method of lockdown and physical distancing. The wold has learnt of the words, work from home. Most of the software companies are preferring work from home, educational institutes are doing online classes etc. Most of the household with working women are seeing women working from home. Surprisingly the lockdown has seen a decrease in the papers published by women. The household work has in this crisis fallen on women and they are the one responsible for juggling career and home. In this respect it is important and heartening that two women have shared the nobel prize for chemistry in the year 2020 . Prior to this there were only 5 women chemists who have received the Nobel prize. Madam Curie was the first woman to win a Nobel prize alone, in 1911 for her second Nobel prize in Chemistry for the discovery of Radium. In 1964 Dorothy Crowfoot Hodgkin again won the Nobel prize unshared for using X-ray to determine structures of various biochemical molecules. The other three women scientists Irene-Joliot Curie in 1935, Ada E. Yonath in 2009 and Frances Arnold in 2018 won the Nobel prize as part of a team with other male scientists. There are only seven women scientists out of 185 scientists who have won the Nobel prize in chemistry, i.e a mere $3.8 \%$, it shows that the participation of women in the highest echelons of science is still very less[4]. The premiere institute of India Indian Institute of Science (IISc) Bangalore has only $10 \%$ female students as per the latest report. The representation of women in STEM (Science, Technology, Engineering and Management) has always been less. In USA only $33 \%$ of the doctoral degree holders are women and outside USA it is $25 \%$ [5]. This prize shows us that more and more women are breaking the glass ceiling. However it should be remembered that for a person of science, their main identity is of a scientist, irrespective of their gender. However, socially the reality is different. There is still a taboo of girls studying science subjects. Girls are encouraged to take up subjects of humanities or liberal arts. Difficulty of the subject, use of mathematics, practical work or excursions in curriculum is the various reasons for which girls are discouraged to study science subjects. Girls often do not get a chance to pursue higher studies and their career seriously as the traditional role of women is as a home maker. There is a dearth of role models for young girls in science. The media does not do any justice to this matter. Either the issue of women scientist are not discussed or even when it is discussed, her role as women balancing both family and workplace is given more attention than her achievements as a scientist. This prize and the discussion surrounding it will definitely encourage more girls to study science.

Speed of Research: As per the will of Alfred Nobel, the award is given to the notable achievements of the previous year; however, the gap between the invention and the award is rarely that. The minimum year between the awards have been less than a year for Irene and Frederic Joliot- Curie however, the longest wait has been almost 50 years for Osamu Shimomura. The average gap between the published work and Nobel prize win is almost 20 years[6]. The prize for CRISPER was received mere 8 years after the paper was published. This shows the pace at which science has been progressing in the modern era. The reason for this is development in correspondence, communications and extensive collaboration between laboratories across the world. The advancement of the development of the CRISPER technology from the basic scientific knowledge took lot less time due to that. Another example of the fast paced science has been the way the scientific community of the whole world came together to develop vaccines for COVID-19.

Basic science and development of technology: Scientific research provides us with knowledge that 
helps in development of technology. Dr. Dudna credits her colleague Dr.Jillian Banfield for introducing her to the field of a repeated sequence in bacterial chromosome, that she surmised may have some connection with m-RNA. They started off with all the biochemical and basic fundamental characterization of the proteins, RNA and its combination, which later on turned out to be technically viable. Technical advances help in development of ambitious scientific experiments. A simple technology of cathod ray tube was responsible for the discovery of $\mathrm{X}$ ray a deciphering the structure of DNA. Hence, Science and Technology helps each other in progressing[7].

Division of subjects: Prof Dudna is a biochemist and Prof Charpentier is a microbiologist, but their Nobel prize was in chemistry. The three subjects Chemistry, Microbiology and Biochemistry have traditionally been taught as different subjects with own structured syllabus. It reiterates the fact that these divisions of science are mere, superficial. The main focus is the problem and knowledge is merely a tool to solve the problem at hand, from whichever subject it might come from. Hence, it is important not to be rigid about the scope of the chosen subject. The new National Education Policy of India also encourages interchange of knowledge between different subjects. The concentration of a researcher should be on solving the problem being as creative as possible about the means for it.

Love of Subject: The main motivation of any scientist is to pursue science with objectivity and passion. It is true not only for science but for all other subjects and fields. Regardless of the position in which one serves the subject it is important to study it with love and a childlike curiosity that must last a lifetime. It is important therefore to choose a subject depending on the love for the subject rather than its ability to give a lucrative career in future. Indian families have a tendency to push children to pursue a career path that may not be to their liking. However, in recent times with various new opportunities and access to the world via internet, this tendency is reducing. When students go forward in a subject chosen according to their choice and passion, they can avoid burnout, boredom and frustration in their career and fight even when there is a rough time.

Affordability of the Technology: The world around us has become extremely technical, more so in the advent of the pandemic, where many physical interactions have been replaced by technology. It has made us more aware of the importance of it and the necessity of it to be made available to all strata of the society so that there is no "digital divide". The CRISPER technology has shown remarkable promise to be potentially useful in treating various genetic diseases. Advanced clinical study has been made in treatment for sickle cell anaemia, a genetic blood disorder and inherited childhood blindness. Fortunately the technology is affordable at present. The inventors have the intention of making it available to all. However, it is yet to be seen how it will be mass produced and marketed in the future.

Financial Aspect and Patenting : Unfortunately, a technology as potentially profitable as CRISPER will have its share of controversy. University of California, Berkeley and MIT-Harvard Broad Institute had filed for the patent rights, as the two stalwarts Dr. Jennifer Dudna and Dr. Feng Zhang are from the two institutes respectively. Dr. Dudna, Dr. Zhang and Dr. Emanual Charpentier are a part of a total of 10 companies for the use of the technology or part of it and are all players in the legal battle. In whichever way the patenting rights go, it should not hinder the research in the field both academically and industrially [8].

\section{CONCLUSION}

Any recognition brings with it a set of responsibilities, more so for a prize as prestigious as the Nobel. There are nowadays other prizes financially more lucrative than Nobel prize but it has maintained its tradition of being the most coveted. The Nobel prize for Chemistry this year is unique in many ways. It has brought to focus the position of women in science along with the importance of women education especially in Science. It also showed us how blurred the division of subjects are and the importance of collaboration in science in current research. The prize this year being given to a technological tool brings to fore the controversial world of patenting and the final cost of a viable technology to the needy. This powerful, efficient, easy and affordable tool for gene slicing also brings with it the ethical issues of how far can a researcher go with gene modifications. The opportunity for good and bad is enormous and there is also the effect it can have on biodiversity. The grey areas in environmental laws and laws on genetic modifications have to be reviewed with respect to the progress in the field. The leap to technology from science for CRISPER was very fast. It brings to front the importance of basic research in Science without regards to the outcome. Hence, basic research is any discipline has to be encouraged in governmental levels. Last but not the least this prize as with any other prize in any field shows us that love for a subject should be the only guiding force in choosing a subject so that sustained interest can be maintained in it for long term.

Acknowledgements: Acknowledgement is due to Shri Shikshayatan College. This article was written without any financial assistance. 


\section{REFERENCES}

1. M. Jinek, K. Chylinski, I. Fonfara, M. Hauer, J.A. Doudna, E. Charpentier,(2012) "A programmable dual-RNA-guided DNA endonuclease in adaptive bacterial immunity". Science. 337(6096), p.p:816-21.

2. M. Martinez-Lage, P.Puig-Serra, P.Menendez, R.Torres-Ruiz, S. Rodriguez-Perales, (2018), "CRISPR/Cas9 for Cancer Therapy: Hopes and Challenges", Biomedicines, 6(4),p.p: 105.

3. A.L. Caplan, B. Parent, M. Shen, C. Plunkett, (2015) "No time to waste - the ethical challenges created by CRISPR.” EMBO rep, 16, p.p: 14211426.

4. M. Mahmoudi, J. A. Poorman, J. K.Silver, (2019)," Representation of women among scientific Nobel Prize nominees", www.thelancet.com, Vol 394 November 23.

5. M. Meadows," Where Are All the Talented Girls? How Can We Help Them Achieve in Science Technology Engineering and Mathematics?",(2016), Journal for the Education of Gifted Young Scientists, 4 (2) , p.p: 29-42.

6. https://www.chemistryworld.com/nobel-prize/thedata-behind-the-nobel-prizes/4010453.article (accessed 3.6.2021)

7. H Brooks,(1994), "The relationship between science and technology", Research Policy, 23(5), p.p: $477-486$

8. P. Webber, (2014) "Does CRISPR-Cas open new possibilities for patents or present a moral maze?" Nature Biotechnology, 32(4), p.p: 331333. 